\title{
O SUJEITO DOCENTE DA DIVERSIDADE E DA DIFERENÇA NAS DIRETRIZES CURRICULARES DE FORMAÇÃO
}

\author{
Ann Letícia Aragão Guarany \\ Universidade Federal de Sergipe - UFS, Brasil \\ Lívia de Rezende Cardoso \\ Universidade Federal de Sergipe - UFS, Brasil
}

\begin{abstract}
Resumo
Neste artigo, procuramos discutir como estão dispostas discursividades acerca do sujeito docente para a diversidade e a diferença em diretrizes curriculares para cursos de formação inicial, seus desejos de governo e as subjetivações que pretendem. Argumentamos que, apesar de não estarem restritas à tolerância e ao respeito à diversidade, as diretrizes de 2015 não produzem um sujeitodocente-diferença, elas ampliam os sujeitos a serem considerados e governados, sem mirarem no questionamento das relações que produziram o diverso e o diferente como tal, intencionando um sujeito-docente-diversidade. Por sua vez, as diretrizes de 2019 naturalizam a diversidade utilizandoa como recurso de aprendizagem a ser explorado pelo sujeito-docente-efetivo no apaziguamento de conflitos, das desigualdades e da diferença.
\end{abstract}

Palavras-chave: Diversidade; Diferença; Diretrizes Curriculares Nacionais; Currículo.

\begin{abstract}
In this article, we seek to discuss how discursivities about the teaching subject are arranged for diversity and difference in curricular guidelines for initial teacher training courses, their government desires and the subjectivations that they intend. We argue that the 2015 guidelines do not produce a subject-teacher-difference, although they are not restricted to tolerance and respect for diversity, they expand the subjects to be considered and governed, without aiming to question the relationships that produced the diverse and the different as such, intending a subject-teacher-diversity. In turn, the 2019 guidelines naturalize diversity using it as a learning resource to be explored by the effectiveprofessor-subject in the appeasement of conflicts, inequalities and difference.
\end{abstract}

Keywords: Diversity; Difference; National Curriculum Guidelines; Curriculum. 


\section{Introdução}

$\mathrm{Na}$ última década, a educação brasileira foi marcada por reformas, alterações nas legislações, diretrizes e formulação de bases nacionais comuns. Esse movimento, que acompanhou as mudanças políticas, reflete a educação como campo privilegiado de produção de sujeitos, alvo dos interesses de governo do Estado e do mercado, impactando tanto a educação básica quanto o ensino superior. Os currículos de formação docente têm destaque neste contexto, pois formam para a profissão legitimada socialmente e institucionalmente como especializada nas atividades pedagógicas, para a obtenção dos objetivos de aprendizagem que as diretrizes indicam e na produção de sujeitos sociais desejados.

Para a formação docente, foram produzidas as Diretrizes Curriculares Nacionais (DCN) para Formação de Professores de 2015 como currículo oficial de referência. A DCN de 2015 foi um marco por alterar, em parte, a lógica que estruturava as regulamentações que fomentavam as políticas de formação de educadores até o início dos anos 2000. Isso se deu também em relação a conteúdos como direitos humanos, diversidade e diferença que foram bastante debatidos e questionados quando incorporados às políticas públicas educacionais nos últimos anos (CARDOSO et. al, 2019). A consideração pela diferença, ou mesmo ainda a diversidade, está no centro do campo de contestação curricular atualmente, protagonizando debates cada vez mais intensos entre grupos conservadores e movimentos que representam minorias sociais e políticas antes pouco representadas nas políticas públicas educacionais. Esse movimento de disputa e de retirada de direitos propiciou a revogação deste documento substituindo-o por outro em que a diferença não é citada, a diversidade é naturalizada e "termos" como gênero e sexualidade foram vetados.

No sentido do esvaziamento das discussões sobre as diversidades e diferença, essa nova diretriz curricular foi aprovada através da Resolução CNE/CP n 2 de 20 de dezembro de 2019, homologada em 2020. Além das DCN para a Formação Inicial de Professores para a Educação Básica, foi instituída no documento a Base Nacional Comum para a Formação Inicial de Professores da Educação Básica (BNC-Formação) formulada a partir das competências e habilidades da Base Nacional Comum Curricular - BNCC para a Educação Básica.

Compreender os anseios desses currículos nos ajuda a identificar as subjetivações docentes pretendidas no processo de sua produção. Silva (1995) nos aponta que diferentes currículos produzem diferentes pessoas, não diferenças meramente individuais, mas diferenças sociais, ligadas à classe, à raça, ao gênero. Eles são fabricados em um processo social que envolve interesses, rituais, conflitos, necessidades de legitimação e de controle, propósitos de dominação que também se ligam às diferenças. Os currículos e os objetos dos quais fala são construídos historicamente e historicizar os meios dessas construções, diz-nos Popkewitz (1994), traz importantes consequências para as discussões contemporâneas da reforma escolar, já que os padrões discursivos da escolarização corporificam sistemas de regulação e poder, através de regras de expressão e diferenciação que não podem ser pressupostas, precisam ser historicizadas. 
Nesse movimento de localização e historicização das políticas de formação docente que pretendemos discutir como estão dispostas discursividades acerca do sujeito docente para a diversidade e a diferença em diretrizes curriculares para cursos de formação inicial aprovadas no país, em especial a de 2015 que ainda é o documento que pauta as licenciaturas brasileiras (DOURADO, TUTTMAN, 2019). Buscamos, tanto nas resoluções e pareceres do Conselho Nacional de Educação (CNE) que aprovaram e subsidiaram as diretrizes quanto nos debates que envolveram as formulações dessas políticas, os embates, as exclusões, os ditos e os silêncios que produziram e foram produzidos pelos currículos, apontando as referências discursivas em torno das formas de diversidade e diferença.

A partir dos princípios gerais, objetivos e indicações dispostas nos documentos, discutimos os desejos de governo e as subjetivações docentes pretendidas por essas políticas públicas para compreender como a diversidade e a diferença são operadas na formação docente. Além disso, tais reformas reposicionam questões semeadas no limiar deste século para as políticas de educação brasileiras: É possível um sujeito curricular comum? Como construir o sujeito da diversidade? O que constituiria o sujeito-docente-da-diversidade? Quais as possibilidades que se abrem para o sujeito-docente-diferença?

Entendemos como Corazza (2001b), sob à luz das teorias pós-críticas, que currículo é um discurso que fornece uma das tantas alternativas de formular, interpretar e dar sentidos ao mundo, ele é um modo de subjetivação, assim a análise de seus elementos se vincula às relações de saber-poder que atravessam os corpos e se fixam nas consciências. Apesar de se tratar de currículos oficiais, as discursividades que os constituem circulam na formação docente e, portanto, colocam na ordem discursiva modos específicos de ver e pensar a diversidade e a diferença. Para investigar o currículo como prática subjetivadora, estudamos a dimensão da subjetividade e as práticas de subjetivação a partir das técnicas de produção de objetos e de direção dos humanos através do governo. Para as nossas análises, compreendemos sujeito com base no pensamento pós-estruturalista que questiona o sujeito moderno, autônomo, livre e autoconsciente, vendo-o como um ser corporificado e generificado, temporal, maleável, flexível e submetido estratégias de normalização e individualização (PETERS, 2000).

Diante das análises, argumentamos neste artigo que, apesar de não estar restrita à tolerância, à valorização e ao respeito à diversidade, as DCN-2015 não produzem um sujeitodocente-diferença que aponta para a multiplicidade. Apesar de avanços em relação às DCN2002 - que almejavam um sujeito-docente-técnico e neutro - e à BNC-2019 - que deseja produzir o sujeito-docente-efetividade que naturaliza e se utiliza da diversidade como recurso para os fins de aprendizagem -, tal documento, enquanto tecnologia de governo que amplia os sujeitos a serem considerados e governados, traz um sujeito-docente-diversidade, adicionando identidades outras, sem intentar o questionamento das relações que produziram o existente e impuseram o diverso e o diferente como tal, por mais que as inconclusas adições possam desestabilizar esse centro normalizado. Nos tópicos que se seguem, historicizamos a produção desses currículos, os desejos de governo e o sujeito das DCN e da BNC, para a seguir discutir como diversidade e diferença se incorporam a esses currículos. 


\section{Currículos oficiais para a docência}

Ao analisar as DCN, enquanto currículos direcionados à formação para a docência na Educação Básica, vemos a necessidade de discuti-los enquanto artefatos culturais e tecnologias de governamento. Compreendemos, partindo de Foucault (2011), que a arte de governar está ligada à descoberta de uma verdade e ao conhecimento objetivo dessa verdade, o que implica a constituição de um saber especializado e a formação de uma categoria de indivíduos especializados no conhecimento dessa verdade. Esses currículos buscam a produção de sujeitos específicos, a partir da necessidade do estabelecimento de uma norma que, enquanto política pública, é direcionada universalmente a todos e que seleciona suas inclusões e exclusões a partir de relações de poder.

Como discute Silva (1995), o processo de seleção e organização do conhecimento não pode ser analisado como um inocente processo epistemológico em que acadêmicos, cientistas e educadores desinteressados e imparciais determinam o que ensinar por dedução lógica e filosófica. Assim, o currículo não é constituído de conhecimentos válidos, mas de conhecimentos considerados socialmente válidos. Dessa forma, ao olhar para as diretrizes em questão, necessitamos identificar os conhecimentos selecionados dentro do contexto de produção do documento como resultado de interesses de grupos diversos e estratégias de governamento. Nesse embate, vão se delineando os sujeitos a serem produzidos e governados em movimentos mistos de ausências, ênfases e adições nem sempre convergentes e consensuais.

Mesmo se tratando de políticas públicas institucionalizadas, a noção de governo e governamento que adotamos não deve se confundir com o conceito de Estado. A noção de governo reflete a diversidade de forças e de grupos que têm buscado, de maneiras heterogêneas, controlar a vida dos indivíduos e as condições dentro de territórios nacionais particulares, na busca de diversos objetivos. Nesse sentido, o Estado torna-se uma forma particular que o governo assumiu, e uma figura que não exaure o campo de cálculos e de intervenções que o constituem (MILLER e ROSE, 2012). Assim, as políticas públicas e os currículos por elas produzidos são estratégias de governo e não do governo enquanto sinônimo de Estado.

Uma vez que as DCN para formação docente são objetos da investigação, é pertinente apontar algumas características sobre as mesmas e suas condições de surgimento. A Lei 9.131, de 1995 que criou o CNE, definiu entre as atribuições desse órgão, deliberar sobre as diretrizes curriculares propostas para os cursos de graduação pelo MEC. As DCN substituíram os Currículos Mínimos (CM) que prezavam pela uniformidade dos cursos na vigência da legislação revogada pela Lei de Diretrizes e Bases da Educação Nacional (LDB) - Lei 9.394, de dezembro de 1996 - para permitir maior flexibilidade na organização de cursos e carreiras (BRASIL, 1997).

Desde a LDB muitas diretrizes, planos e bases curriculares foram discutidas e aprovadas no final da década de 90 e nos anos 2000. De acordo com Silva (2010), esse conjunto de ações se justificaram na necessidade de adequar a educação brasileira às mudanças do cenário econômico mundial e local, em torno do desenvolvimento das competências necessárias à 
vida em sociedade e à inserção no trabalho. A partir disso, tecnologias, competências, habilidades e adequação ao mundo do trabalho são categorias centrais nas proposições das reformas curriculares.

Para a formação docente, a primeira diretriz foi aprovada através da Resolução CNE/CP $n^{\circ} 1$, de 18 de fevereiro de 2002, complementada pela Resolução CNE/CP n ${ }^{\circ}$, de 19 de fevereiro de 2002 que definiu a carga horária dos cursos. Na esteira da eficiência e produtividade, necessárias à competitividade do mercado e à lógica neoliberal, a Diretriz foi formulada com a centralidade para as "competências necessárias à atuação profissional" a serem desenvolvidas para "garantir a constituição das competências objetivadas na educação básica" (BRASIL, 2002, p.2). Não há entre os conteúdos e competências a serem desenvolvidas questões de diversidade ou aspectos que sejam inerentes ao contexto das escolas ou de discentes, apenas menciona o acolhimento e o trato da diversidade como princípio, repetindo o que há na LDB.

Garcia (2015) coloca que os currículos da formação docente nesse período são de cunho gerencialista, estando a docência reduzida à tarefa de execução eficiente de currículos e pacotes instrucionais previamente estabelecidos para obtenção de resultados pelos quais docentes serão cobrados e podem ser recompensados. Esses resultados deveriam estar expressos em índices de desempenho, medidos por sistemas de avaliação padronizados com características regulatórias e conservadoras. Para a autora, o discurso curricular oficial consagra uma pedagogia centrada nas competências do saber-fazer, nas ações e formas de atuação, na resolução de problemas no âmbito do ensino e da aprendizagem e na forma de conhecimentos e habilidades aplicadas.

Após treze anos, em um contexto político que permitiu que outras formações discursivas tivessem maior destaque nas disputas políticas e a partir de consultas e debates participativos no CNE, foi aprovada a Resolução $\mathrm{CNE} / \mathrm{CP} \mathrm{n}^{\circ} 2$, de $1^{\circ}$ de julho de 2015 . Essa resolução, em suas considerações iniciais, aponta o currículo como um "conjunto de valores propício à produção e à socialização de significados no espaço social” (BRASIL, 2015a, p.2). O currículo, segundo o documento, deve contribuir "para a construção da identidade sociocultural do educando, dos direitos e deveres do cidadão, do respeito ao bem comum e à democracia, às práticas educativas formais e não formais e à orientação para o trabalho" (BRASIL, 2015a, p.2).

A diretriz não se baseia em competências a serem desenvolvidas, enfatizando os processos, as dimensões e os conhecimentos relacionados à ação docente, a partir do reconhecimento do direito estudantil à educação de qualidade. Aponta para a consideração do contexto da escola e as características humanas, inclusive em suas diversidades. Naquele cenário da educação brasileira, as competências estavam dando lugar ao direito da criança à educação, à aprendizagem e ao desenvolvimento. Freitas, Silva e Leite (2018) discutem como a partir de 2013 a aprendizagem enquanto direito universal passa a ser central nos documentos oficiais para a educação básica.

O prazo inicial estabelecido pela resolução de 2015 para que os cursos de graduação se adaptassem foi de dois anos, portanto, se encerraria em julho de 2017. Porém, o prazo foi adiado três vezes até dezembro de 2019 justificado por dificuldades apresentadas pelas 
instituições de ensino superior em reformular seus currículos, mas principalmente pela vinculação dos cursos de formação docente à BNCC para a educação básica, que na ocasião do primeiro adiamento ainda não havia sido plenamente aprovada.

A alegação que fundamentou a decisão do Conselho trouxe preocupação, pois a versão aprovada da BNCC para o Ensino Fundamental no fim de 2017 mostrou que alguns dos conteúdos obrigatórios para a formação docente foram alvos de protestos de grupos conservadores que pressionaram o MEC a suprimir termos como gênero e orientação sexual de trechos específicos do documento. Este movimento já havia ocorrido na atualização do Plano Nacional de Educação que foi aprovado sem o trecho que falava sobre desigualdades de gênero, deixando generalista o combate às formas de discriminação, sem citar exatamente quais. O mesmo ocorreu com a BNCC para o Ensino Médio aprovada em dezembro de 2018 que além da retirada dos termos retomou alguns princípios como a noção de competências que não estava presente nas duas primeiras versões da BNCC, mas foi reforçada na última.

$\mathrm{O}$ argumento da necessidade de seguir a BNCC ganhou força, o que se reflete na revogação das DCN de 2015, mesmo diante de muitos protestos de educadores e pesquisadores em educação e sem tempo hábil de avaliação das primeiras turmas formadas com base na Diretriz há 4 anos aprovada. A resolução CNE/CP n ${ }^{\circ}$, de 20 de dezembro de 2019, homologada em abril de 2020, que instituiu a Base Nacional Comum para a Formação Inicial de Professores da Educação Básica (BNC-Formação), se estrutura nas competências e habilidades dispostas da BNCC.

Esse breve histórico nos permite localizar e apresentar os documentos legais que serão analisados em relação à forma como diversidade e diferença vêm sendo apresentadas ao longo das diretrizes para formação docente, tendo a resolução de 2015 como norte que guiará a busca e permitindo identificar os contrastes com a diretriz anterior e com a recém-aprovada BNC.

\section{Subjetividades e governo docente nas diretrizes curriculares de formação}

Algumas resoluções que surgiram no início do século XXI, trouxeram para as políticas públicas em Educação sujeitos e narrativas antes não "autorizados", principalmente a partir da ascensão de um governo que se reconhece mais à esquerda em 2004. As DCN de 2015 reúnem muitas das premissas desses documentos legais que as antecederam, dos quais podemos destacar: DCN para a Educação das Relações Étnico-Raciais e para o Ensino de História e Cultura Afro-Brasileira e Africana de 2004; as Diretrizes Nacionais para a Educação em Direitos Humanos; as DCN para a Educação Escolar Quilombola na Educação Básica; DCN para a Educação Escolar Indígena na Educação Básica e as Diretrizes para Formação de Professores Indígenas, todas em 2012, entre outras. Algumas tinham bases já formuladas em documentos legais anteriores, mas foram mais estruturadas através dessas diretrizes específicas. 
Assim, ganharam espaço alguns conteúdos obrigatórios não citados na antiga diretriz de formação docente de 2002, como direitos humanos, diversidades étnico-racial, de gênero, sexual, religiosa e de faixa geracional. Essa incorporação revela um movimento de busca por abarcar outros indivíduos e grupos antes não considerados nas políticas públicas em educação. A “inclusão” de sujeitos, conceitos, princípios e conhecimentos foi impulsionada na Secretaria de Educação Continuada, Alfabetização, Diversidade e Inclusão - SECADI por representantes de grupos em defesa dos Direitos Humanos e de organizações específicas em prol de indivíduos historicamente excluídos das decisões políticas estatais que passaram a ter espaço e constituíram a própria equipe da administração pública. Nesse momento, esses agentes legitimados deram força a formações discursivas pautadas no combate à discriminação racial, étnica, de gênero, sexual, social, religiosa e cultural.

Segundo Henriques, Franco e Teles (2006), em um estudo feito pela citada SECADI, um dos obstáculos enfrentados para identificar e combater os efeitos negativos da discriminação no ambiente escolar é a ausência de tratamento adequado da temática nas escolas e no ensino superior. Assim, as resoluções são respostas ao enfrentamento dos problemas identificados como forma de governar os indivíduos na redução da discriminação e intolerância. Também, no campo do currículo, com a potencialização dos Estudos Culturais nas últimas três décadas, as questões do multiculturalismo tornaram-se centrais na teoria educacional crítica e nas pedagogias oficiais, ainda que tratadas como temas transversais (SILVA, 2000).

De acordo com Miller e Rose (2012), quando um aspecto da conduta individual ou coletiva passa a ser considerado responsável por um problema, essa conduta precisa se tornar maleável à intervenção e estar suscetível a uma série de técnicas ou de instrumentos racionalizados que permitam agir sobre ela e transformá-la potencialmente. O problema pode ser enquadrado dentro de uma linguagem comum ou que permita o diálogo podendo posteriormente ser formulado em termos de conhecimento mais ou menos formalizado, como nos currículos oficiais.

Acreditamos ser importante considerar que nesse movimento de incorporação há um determinado sujeito, ou como mencionado nos documentos legais, "uma identidade sociocultural" que é ativada enquanto norma e centro do qual parte a diversidade. Ela é, como diz Silva (2000), a forma privilegiada na hierarquização das identidades e das diferenças que nem sequer é vista como uma identidade em torno da qual as outras são construídas como tal, mas simplesmente como a identidade de forma tão homogeneizadora que se torna invisível.

As políticas públicas, na visão de Macedo e Ranniery (2018), atuam no sentido de tornar hegemônicas certas posições particulares, delimitando quem tem direito a ser reconhecido e produzindo efeitos como identificações subjetivas ou endereçamentos. Essa definição do sujeito padrão a ser formado nas políticas públicas brasileiras, de acordo com os autores, é marcada por uma mesmidade que marca o público como endereçamento das políticas curriculares recentes. Ela se define prioritariamente na própria decisão sobre como as políticas públicas devem agir mediante normas centralizadas direcionadas a todos.

Todas essas DCN que usamos como eixo de análise remontam os princípios e fundamentos da Constituição da República de 1988 que estão presentes também na LDB de 
1996, tendo como centros comuns: a igualdade, a liberdade, a tolerância, a democracia, a preparação para trabalho e as práticas sociais. Mesmo na busca por reconhecer e valorizar a diversidade, continuam vinculadas aos princípios da universalidade do "todos" enquanto público-alvo e aos interesses gerais de formação de sujeitos-padrão, a partir de identidades definidas a priori.

Na DCN de 2015, a cidadania se configura princípio, base e objetivo final da educação, se concretizando mais fortemente no exercício do trabalho. Uma das considerações da resolução é a contribuição do currículo para a "construção da identidade sociocultural do educando, dos direitos e deveres do cidadão, do respeito ao bem comum e à democracia, às práticas educativas formais e não formais e à orientação para o trabalho" (BRASIL, 2015a, p.2). O primeiro dos objetivos elencados para o egresso das licenciaturas é dar significado e relevância aos conhecimentos e vivência da realidade social e cultural, direcionado ao que coloca como exigência da educação: "o exercício da cidadania e qualificação para o trabalho", (BRASIL, 2015a, p.6). Assim, as instituições educativas são definidas como organizações complexas "na função de promover a educação para e na cidadania" (BRASIL, 2015a, p.7).

O sujeito padrão deve ser universal e inquestionavelmente um cidadão, democrático e trabalhador. Gallo (2018) percebe como nos últimos trinta anos a democracia e do trabalho são centrais nos documentos da política educacional, mesmo com diferentes partidos políticos ocupando o executivo federal, o que demonstra como o projeto político da governamentalidade democrática não é uma ação partidária, mas de governo. A cidadania entra para sustentar a necessidade de uma estrutura democrática participativa, após sair de décadas de regime de exceção. Assim, "somos subjetivados como cidadãos para que possamos ser democraticamente governados" (GALLO, 2018, p.219).

O sujeito-cidadão, para Bampi (2000), se cidadaniza a partir de técnicas de governo ligadas a seus desejos e anseios por progresso, que produz sujeitos de necessidades e de aspirações, mas também objetos de governo, regulados em suas condutas através da ativação de ideais, esperanças e temores. Os indivíduos se autogovernam como certos tipos de sujeitos de saber, objetivados e guiados pelas sedutoras promessas de cidadania, de liberdade, de um mundo sem arrogância, sem injustiça e sem discriminação. Nesse sentido, as DCN de 2015 configuram-se como convite à construção de cidadãos.

Considerando a racionalidade neoliberal em que a cidadania se define ainda mais em termos de mercado, a figura do trabalhador aparece como face importante do sujeito-cidadão. Trabalhar para ser útil à sociedade e à nação, se insere posteriormente, a partir das transformações das relações econômicas e sociais, na lógica do mercado regida por princípios globais e competitivos. $\mathrm{O}$ trabalhador passa a ser alguém ativo que precisa se autogerir na busca e construção de sua própria felicidade. Miller e Rose (2012) abordam como o neoliberalismo delimita "novos" sujeitos de governo como indivíduos ativos em busca de empreender a si mesmos, maximizar sua qualidade de vida, felicidade e realização através de escolhas que darão significado e valor à vida, enquanto criaturas de liberdade, independência e autonomia. 
Além do contundente direcionamento para a cidadania, democracia e preparação para o trabalho, vemos nas diretrizes a preocupação de que ação docente deva possibilitar condições para o exercício do pensamento crítico, a resolução de problemas, o trabalho coletivo e interdisciplinar, a criatividade, a inovação, a liderança e a autonomia, características tão caras ao sujeito neoliberal. Um casamento entre neoliberalismo e cidadania para formar sujeitos governáveis. Nesse sentido, essas outras "palavras" para definir o discente a ser produzido emergem da DCN analisada e de outros textos legais desse período temporal que não estavam presentes na LDB, nem na resolução de 2002 que orientava a formação docente até então, como: emancipação (BRASIL, 2015a, p.4); autonomia do aluno (p.7); criticidade (p.6); criatividade (p.6); liderança (p.6); e inovação (p.6).

A resolução de 2015 se liga fortemente às necessidades do mercado em relação ao sujeito que deve ser produzido e governado de modo a se encaixar em novas demandas e necessidades, atualizando sob a roupagem da liberdade e autonomia o sujeito neoliberal que deve agir sobre si mesmo na busca para ser líder, criativo, crítico e emancipado. As duas últimas características remontam à promessa de libertação e emancipação através do exercício da criticidade proposta pelas teorias críticas ainda hegemônicas, especialmente no campo da educação. Para Corazza e Tadeu (2003), a promessa de emancipação (re)introduz, por outro viés, a fantasia de um sujeito soberano no comando de seus atos e capaz de uma consciência plena, restaurando uma essência que foi corrompida e alienada.

Em nossa busca por esse sempre incompleto e inconcluso sujeito das políticas públicas educacionais, temos que destacar que, como nos diz Miller e Rose (2012), não há sujeitos universais de governo, mas subjetivações, como um estilo de ação sobre a ação, pois os que devem ser governados precisam ser sempre concebidos como crianças a serem educadas ou sujeitos sociais aos quais devem ser concedidos direitos e deveres, indivíduos autônomos a serem assistidos. A nossa própria ideia do sujeito humano como individuado, capaz de escolhas, com aptidões de autorreflexão e em busca de autonomia, é um resultado de práticas de subjetivação, não a base histórica para criticar tais práticas.

Para governar os sujeitos, é importante conhecê-los, é preciso criar estratégias que os tornem efeitos dos processos de subjetivação do currículo. Para isso, o sujeito deve se reconhecer nele para melhor aderir à verdade que o constitui, constuir verdades sobre si mesmo e dirigir sua própria conduta e a dos outros a partir dos desejos de governo e subjetivação desse currículo.

Foucault (2011) entende que o poder consiste em relações complexas que envolvem técnicas racionais que integram as técnicas de coerção e técnicas de si. Gallo (2018), a partir de Foucault, nos fornece elementos para pensar como a educação é um espaço privilegiado do manejo das técnicas para subjetivação dos estudantes a partir da governamentalidade que se dá na articulação das técnicas de dominação e técnicas de si. A educação sujeita, produz sujeitos que também devem agir sobre si mesmos, no próprio processo de assujeitamento, produzindo ações de subjetivação.

O sujeito docente que se pretende nas DCN de 2015, e que deve agir sobre discentes a partir desse currículo, é alguém que: em sua ação educativa necessita de "conhecimentos específicos, interdisciplinares e pedagógicos" (BRASIL, 2015a, p.3); deve possuir "sólida 
formação científica e cultural do ensinar/aprender" (p.3); pode trabalhar na "gestão educacional" (p.4); possui uma "formação mínima exigida por legislação" (p.4); tem "visão ampla do processo formativo" (p.6); usa de forma "competente as Tecnologias de Informação e Comunicação (TIC)" (p.6); planeja, executa, acompanha e avalia políticas, projetos e programas educacionais (p.8); contribui "para a consolidação de uma nação soberana, democrática, justa e inclusiva" (p.4); promove "a emancipação dos indivíduos e grupos sociais" (p.4); identifica "questões e problemas socioculturais e educacionais, com postura investigativa, integrativa e propositiva" (p.8); pesquisa e conhece seus "estudantes e suas realidades socioculturais" (p.8); domina "os conteúdos específicos e pedagógicos e as abordagens teórico-metodológicas do seu ensino, de forma interdisciplinar e adequada às diferentes fases do desenvolvimento humano"(p.8); utiliza "instrumentos de pesquisa adequados" (p.8); possui conhecimento sobre o ser humano e práticas educativas, "incluindo conhecimento de processos de desenvolvimento de crianças, adolescentes, jovens e adultos, nas dimensões física, cognitiva, afetiva, estética, cultural, lúdica, artística, ética e biopsicossocial" (p.10); faz "diagnóstico sobre as necessidades e aspirações dos diferentes segmentos da sociedade relativamente à educação" (p.10); reflete criticamente sobre a própria prática e a aperfeiçoa (p.14); é valorizado enquanto profissional e tem um plano de carreira (p.15).

Dentre os elementos que devem constituir esse especialista docente, destacamos nas citações em itálico trechos que se referem à necessidade de escrutinar discentes para escolher as estratégias que permitam torná-los objetos de saber que podem ser administrados e regulados. A primeira questão a ser discutida é o domínio de conhecimentos sobre os aspectos psicológicos, cognitivos e emocionais, que já estavam presentes nas DCN de 2002. A segunda, mais presente nessa resolução, é a identificação dos aspectos sociais e culturais de estudantes que também devem ser averiguados, questionados e considerados.

O conhecimento docente de conteúdos da psicologia e dos estágios do desenvolvimento o coloca em posição de especialista, o que, segundo Varela (2000), limita o controle dos alunos sobre sua aprendizagem, pois seus avanços, retrocessos e interesses ficam para eles distantes e alheios. Assim, na promoção da criatividade, liberação e autonomia do estudante, são potencializadas a dependência e a subordinação. O psicopoder "baseia-se em tecnologias cuja aplicação implica em uma relação que torna os alunos tanto mais dependentes e manipuláveis quanto mais liberados se acreditem" (p.102). O que se pretende, ainda segundo a autora, é a produção de personalidades flexíveis sensíveis, polivalentes e capazes de autocorrigir-se e autoavaliar-se funcionais a um neoliberalismo consumista que precisa de sujeitos moldáveis e diversificados em um mercado de trabalho instável e flexível que precisa de trabalhadores preparados e disponíveis para funcionar.

Para conhecer as realidades socioculturais dos alunos, o sujeito docente deve pesquisálos. Neste exercício, nos diz Bampi (2000), a pedagogização do cotidiano dos indivíduos viabiliza meios pelos quais suas condutas podem ser socializadas, maximizadas e moldadas. Esta ação envolve efeitos sedutores, libertadores e emancipatórios que fundamentam teorias pedagógicas críticas e que sugerem, segundo a autora, que ao falar de sua opressão e reconhecer sua condição de subordinado, o indivíduo pode trilhar o caminho para o 
esclarecimento, para a libertação, via uma pedagogia, e assim incitam a vontade dos indivíduos de transformar a sociedade, mas também os modificam. Essas teorias põem em funcionamento técnicas de governamentalidade que desempenham um papel constitutivo na produção de sua subjetividade.

Esses e demais elementos constituintes do sujeito-docente das DCN ativam algumas das características do sujeito-docente-técnico que era central nas DCN de 2002, pois as dimensões técnicas parecem ter sido configuradas enquanto necessárias ao docente natural e legitimado, mas o desloca para um sujeito-docente-diversidade-comum. Sendo o endereçamento comum parte do que foi delimitado enquanto necessidade para qualquer política pública, até agora, o comum será retirado dos termos e passaremos a buscar mapear mais detalhadamente como o sujeito-docente-diversidade, a que se propõe as DCN de 2015, passa a se configurar na diretriz.

\section{O sujeito-docente-diversidade nas Diretrizes Curriculares Nacionais}

Junto às aptidões já elencadas, o docente também é apontado no documento como alguém que se "atenta ao reconhecimento e à valorização da diversidade", sendo "contrário a toda forma de discriminação" (BRASIL, 2015a, p.4); é um agente formativo de cultura (p.5); contribui "para a superação de exclusões sociais, étnico-raciais, econômicas, culturais, religiosas, políticas, de gênero, sexuais e outras" (p.8); tem "consciência da diversidade", e; "respeita as diferenças" (p.8).

Paralelo aos docentes das escolas-padrão que aliam as competências gerais ao respeito à diversidade, existem docentes de outras escolas: os indígenas e aqueles que venham a atuar em escolas indígenas, docentes da educação escolar do campo e da educação escolar quilombola. Tais profissionais devem considerar todas as aptidões descritas para o sujeitodocente-técnico ou sujeito-docente-padrão e ainda, "dada a particularidade das populações com que trabalham e da situação em que atuam", devem ser agentes interculturais para a valorização e o estudo de temas específicos relevantes.

Assim, para além das ofertas regulares de educação há especificações para as modalidades de educação escolar indígena, do campo e quilombola no documento, ressaltando que nas DCN de 2002 não havia a descrição das modalidades. A educação escolar indígena deve considerar as normas e o ordenamento jurídico próprios, com ensino intercultural e bilíngue, o que já se encontravam na LDB. Para a educação escolar do campo e quilombola as DCN de 2015 definem considerar a diversidade étnico-cultural de cada comunidade.

As diretrizes para formação de professores aprovadas em 2002, tratavam os conhecimentos exigidos nos cursos de formação de forma mais generalista e técnica, indicando apenas o debate de questões culturais, sociais, econômicas e o conhecimento sobre desenvolvimento humano e docência. Essa diretriz menciona, apenas como orientação, o acolhimento e o trato da diversidade. Dessa forma, a resolução de 2015 apresenta alterações expressas no próprio parecer que a subsidiou, o qual afirma que tais diretrizes devam fazer 
repensar a educação básica e suas políticas para que sejam pautadas na diversidade, direitos humanos e inclusão, reconhecendo a "educação básica como direito universal, espaço de construção identitária dos sujeitos, respeitando e valorizando as diferenças" (BRASIL, 2015b, p.9).

O parecer ressalta ainda que o processo formativo exige a liberdade e pluralidade, através do reconhecimento e valorização das diferenças nas suas diversas dimensões, em especial as diversidades étnico-racial, sexual, de gênero e identidade de gênero, geracional, cultural e regional como princípios de equidade, além das diferenças cognitivas e físicas, não devendo se limitar ao respeito e à tolerância, mas como parte do processo formativo que impacte o currículo, a prática pedagógica e a gestão escolar (BRASIL, 2015b).

Ao considerar as diversidades e as diferenças não apenas no sentido da tolerância e respeito, mas da valorização, as DCN superam algumas das críticas que têm sido feitas aos documentos de órgãos e instituições que vêm "incluindo" as diversidades em seus programas, projetos e reformas educacionais. A diversidade se configura enquanto parte constituinte do processo de formação, passando a pretender um sujeito-docente-diversidade: um sujeito que inclui o maior número possível de identidades, que respeita as individualidades, que tolera os diferentes, mas ainda sem contestar a matriz de produção de diferenças e hierarquizações.

Silva (2000) discute que quando o multiculturalismo em educação é abordado como questão de tolerância e respeito, as diferenças culturais são retratadas como questão de consenso, de diálogo ou comunicação, o que impede que vejamos a identidade e a diferença como processos de produção social que envolvem relações de poder. $\mathrm{O}$ autor aponta algumas estratégias que constantemente são adotadas nas escolas em referência às diversidades e diferenças culturais. Uma delas chamada de liberal consistiria em apresentar as expressões culturais como movimentos inerentes à dimensão do humano sem abordar as relações de poder e os processos de diferenciação que produzem a diferença. Outra abordagem seria a terapêutica que mira na correção de atitudes individuais consideradas inadequadas como o preconceito e a discriminação, através de atividades de conscientização. A estratégia, que acredita ser a mais utilizada, consiste em apresentar uma visão superficial e distante das diferentes culturas como algo curioso e exótico, o que reforça o "lugar do outro". $\mathrm{Na}$ superação dessas estratégias, Silva (2000) advoga por uma política pedagógica e curricular que permita não apenas reconhecer e celebrar a diferença e identidade, mas questioná-las.

Rodrigues e Abramowicz (2013), ao debater a diversidade e diferença em políticas públicas em educação, afirmam que o reconhecimento das várias identidades e/ou culturas atravessado pela tolerância significa manter intactas as hierarquias do que é considerado hegemônico. Dessa forma, a diversidade pode ser entendida como uma forma de governamento exercida pela política pública no campo da cultura, uma estratégia de apaziguamento das desigualdades e de esvaziamento do campo da diferença, já que a diferença teria como função borrar as identidades e quebrar as hegemonias.

A diversidade entra nas políticas públicas brasileiras em educação modificando princípios, mas ainda mantendo algumas bases dos sujeitos-padrão envolvidos na escolarização e na ação docente. Essa abordagem pode mudar quem é representado, mas não as regras de classificação e normalização. Esses "outros" sujeitos se inserem nos desejos e 
nas relações de poder que operam na educação ainda como "o outro" ao se incorporar na lógica universal, o que pode permitir formas de governo mais efetivas a partir do silenciamento dos conflitos inerentes às desigualdades e forçando um aparente consenso.

É nesse sentido que Walsh (2009) discute a existência de uma interculturalidade funcional a serviço do multiculturalismo neoliberal, que desde os anos 90 do século passado passou a pautar as políticas públicas, reformas educativas e constitucionais na América Latina tendo como tema a diversidade cultural. Mesmo vista como resultado das lutas dos movimentos sociais-ancestrais em suas demandas por reconhecimento e direitos, essa incorporação tem se ligado aos desenhos globais do poder, capital e mercado. Permitem que órgãos e Estados possam agir sobre povos e territórios, sob o pretexto da inclusão, para apagar as diferenças e dirimir conflitos, atuando junto às comunidades e incorporando aspectos de sua diversidade cultural em estratégias de desenvolvimento baseadas na coesão social, no individualismo e na competitividade, em prol de um mercado global e ideais universalizados.

Conhecer o diverso, criar formas de medi-lo, de avaliá-lo, de identificar dimensões e especificidades antes não consideradas, são tecnologias de governo que agem a partir da diversidade para produzir currículos. Mas a consideração para com esse Outro, caso sejam expostos os modos pelos quais foi produzido enquanto $\mathrm{O}$ diferente, também pode revelar a existência e o processo de fabricação desse centro do qual se parte, possibilitando multiplicálo infinitamente e, quem sabe, implodi-lo. Não temos ainda elementos para discutir como essas diretrizes foram incorporadas aos currículos dos programas de formação docente ou os impactos na educação básica, o que revelaria mais sobre a questão.

A resolução que aprova DCN de 2015 não define os conceitos de diversidade e de diferença ou como se relacionam com a identidade. Ao analisarmos como estes termos aparecem em alguns trechos podemos buscar identificar algum tipo de fundamento, como quando trata do "respeito às diferenças, reconhecendo e valorizando a diversidade étnicoracial, de gênero, sexual, religiosa, de faixa geracional, entre outras"(BRASIL, 2015a, p.6), para depois marcar muito do que aponta como diversidade enquanto diferenças: "respeitando as diferenças de natureza ambiental-ecológica, étnico-racial, de gêneros, de faixas geracionais, de classes sociais, religiosas, de necessidades especiais, de diversidade sexual, entre outras" (BRASIL, 2015a, p.8). Assim ocorre no parecer em que se embasou a resolução quando afirma que "o reconhecimento e a valorização das diferenças, nas suas diversas dimensões" produzem implicações no currículo, na prática pedagógica e na gestão da instituição educativa não devendo se limitar ao "respeito e à tolerância nas relações interpessoais" (BRASIL, 2015b, p.9).

A diversidade aparece como dimensão da diferença, também como aparente sinônimo ou ainda como complemento dos marcadores de diversidade, o que reforça a afirmação de Silva (2000) que identidade e diferença foram reconhecidas como objetos de conhecimentos nas normativas legais, mesmo na ausência de uma teoria da identidade e da diferença. As DCN de 2015 enumeram enquanto formas, tipos, possibilidades e marcadores de diversidades questões sexuais, de gênero, raciais, religiosas e geracionais, enquanto a 
diferença inclui classe social, natureza ambiental-ecológica, necessidades especiais e diferenças cognitivas e físicas.

Podemos inferir que as diversidades se relacionam mais diretamente, a partir das DCN, com marcadores "comportamentais" e "identitários" e a diferença aparece mais ligada a marcadores socioespaciais ou características biológicas. O que poderia indicar que a menção à diferença não se dá no sentido das teorias que desafiam a identidade, mas que se refere aos diferentes marcadores identitários, incluindo os que têm relação com características biológicas do corpo ou do espaço que o indivíduo ocupa, ampliando as formas em que se apresentam as diferenças para além do que define como diversidade.

Apesar da aparente semelhança, diversidade e diferença não partem do mesmo centro e dos mesmos pressupostos, como nos diz as teorias pós-críticas e a chamada filosofia da diferença. A diversidade parte de identidades, mesmo que sejam inúmeras e não fixas, enquanto a diferença afirma a multiplicidade para tirar o foco da identidade. Paraíso (2010) afirma que a identidade ainda tem prestígio no campo do currículo, visto como espaço de produção identitária. Segundo ela, o tema ganhou destaque nas produções sobre currículo no país a partir dos anos 90, e, posteriormente, com as contribuições dos Estudos Culturais, Feministas e Pós-coloniais, a identidade ganhou qualidades multifacetadas, fragmentadas, diversificadas, híbridas e pós-modernas para atender sua dispersão. Mas mesmo quando pensada em sua relação com a diferença, é a identidade que está em foco, como vemos nas DCN.

A partir do que manifestam Corazza e Tadeu (2003), devemos afirmar a superioridade da diferença sobre a identidade, privilegiar a multiplicidade ao invés da diversidade, nos negar a reduzir a diferença à negação e à contradição. Precisamos "defender os direitos da variação, da singularidade e da multiplicidade, diante das reivindicações da semelhança, da equivalência, da analogia e da unicidade" (p.16). A diversidade é estática, limita-se ao existente enquanto um dado da natureza ou da cultura que reafirma o idêntico. Por sua vez, a multiplicidade é ativa, é fluxo, é produtiva, como uma máquina de produzir diferenças, estimula a diferenças irredutíveis à identidade, que se recusam a se fundirem com o idêntico.

A afirmação da multiplicidade para as políticas, ou o ainda reconhecimento e valorização das diferenças e diversidades a partir de variadas identidades, podem trazer possibilidades outras e potencialidades que possam multiplicar os desejos de um sujeito-docente-diferença. Macedo e Ranniery (2018, p.752) declaram que:

Se esses enredamentos parecem arriscar as estruturas fantasmáticas do universalismo abstrato, atualizadas pelo neoliberalismo globalizado, é porque dessacralizam as políticas públicas quando as transformam em um emaranhado vital de escalas, tempos e seres heterogêneos localmente entrelaçados, nunca plenamente formados, sempre constituídos em relação.

Seguindo na ideia dos autores, esse emaranhado de seres e de vidas pode permitir a rearticulação das políticas em educação para o desfazer do cidadão humano trabalhador abstrato e tornar cada vez mais, mas nunca permanentemente, problemáticos os 
compromissos das políticas curriculares com a normatividade. Diz-nos Corazza (2001a) que ao exercer nossa vontade criadora poderemos inventar, mais uma vez, a diferença. Para isso, temos que perguntar se o que vimos e dissemos nas propostas curriculares é tudo o que pode ser visto e dito. Sabendo que se o que existe chegou até aqui assim, é porque, assim foi criado e poderá ser traçado de outros modos.

\section{O sujeito-docente-efetivo na Base Comum Nacional}

Para Cardoso et. al. (2019), após um primeiro esforço na construção de normativas, parâmetros e diretrizes que promovessem a inserção de grupos minoritários e a educação para a tolerância, houve no Brasil um segundo movimento das políticas educacionais na busca por minimizar as desigualdades a partir de marcadores culturais. Nesse momento, porém, pouco se problematizou as matrizes discursivas de produção das desigualdades e foram abertas as possibilidades de intervenção da onda conservadora nas políticas ainda tão frágeis, produzindo-se um movimento de retrocessos nas mais recentes normativas.

Esse movimento de disputa e de retirada de direitos que já havia se iniciado, mesmo no momento da produção das DCN de 2015, agora encontra terreno mais fértil com a ascensão de parlamentares conservadores que culminou na ocupação dos cargos de maior poder no país. Esse contexto ameaçou a validade deste documento, revogando-o e substituindo-o por outro em que a diferença não é citada e a diversidade não é parte do processo formativo, mas um recurso de aprendizagem e uma realidade natural a ser observada na relação com o outro de forma empática e respeitosa, como discutiremos a seguir.

A BNC se coloca como solução prescritiva para o problema da educação, uma vez que esses "referenciais para a formação docente consistem em descrever o que os professores devem saber e ser capazes de fazer" (BRASIL, 2019 p.9). O problema educacional é constituído a partir de estudos, estatísticas e indicadores internacionais que apontam a falta de qualidade do ensino brasileiro e os professores como um dos pilares do problema/solução. Os dados que evidenciariam o problema se encontram nos argumentos colocados no parecer que fundamentou a resolução, em que são apresentadas as "evidências dessa asserção" a partir do "resultado de experiências internacionais" (BRASIL, 2019 p.9).

Assim, busca legitimar a necessidade de que os docentes se responsabilizem pela sua formação contínua e sua atuação de forma a garantir as aprendizagens essenciais previstas na BNCC e o desenvolvimento das competências e habilidades previstas para "efetivas aprendizagens" (BRASIL, 2019). A BNC-Formação reafirma a centralidade do desenvolvimento de competências, declara menos princípios e fundamentos, sendo mais prescritiva, pragmática e técnica. Concordamos com Pires e Cardoso (2020) ao afirmarem que o perfil docente esperado pela BNC é o docente prático, sem aporte teórico para refletir sobre a realidade e questioná-la, o que chamamos aqui de docente-efetivo.

De acordo com Silva (2010), a organização com base em competências a serem desenvolvidas, compõem uma perspectiva funcionalista dos processos de escolarização que se assemelham às teorias pedagógicas em voga desde os anos 60, e que estiveram presentes 
nas normativas curriculares nos anos 90, as quais reduzem a formação humana por desconsiderar sua dimensão histórico-cultural. O sujeito-docente-técnico das DCN de 2002 atualiza-se para o sujeito-docente-efetivo da BNC de 2019, um sujeito que não apenas possui as técnicas, mas as coloca em prática da melhor forma possível para atingir os objetivos das políticas.

$\mathrm{O}$ uso do conceito de efetividade não se dá por acaso, mas porque se repete na $\mathrm{BNC}$ (BRASIL, 2020) como quando pretende a "aplicação dos procedimentos de avaliação de forma que subsidiem e garantam efetivamente os processos progressivos de aprendizagem" (p.6); o planejamento de "ações de ensino que resultem em efetivas aprendizagens" (p.13, p17); a proposição "efetivamente" do "desenvolvimento de competências e educação integral dos estudantes" (p.19). A promoção da efetividade se articula com discursos da administração e gestão empresarial o que aproxima os resultados dos atos educacionais a dados mensuráveis. A efetividade, nos discursos da gestão administrativa, é a capacidade de fazer uma coisa ou atingir um objetivo, que seria a eficácia, da melhor maneira possível, com os melhores recursos e meios, que define eficiência. Mais recentemente, a literatura especializada incorporou esse terceiro conceito, mais complexo que a eficiência e a eficácia por combinar os dois se concentrando na qualidade do resultado e na necessidade de certas ações públicas (CASTRO, 2006).

Nesse sentido, encontramos na BNC (BRASIL, 2020) a responsabilidade não do sistema educacional, das políticas, da sociedade, da formação, mas do sujeito-docente-efetivo de buscar os conhecimentos e experiências "que lhe possibilitem aperfeiçoamento profissional e eficácia e fazer escolhas alinhadas ao exercício da cidadania, ao seu projeto de vida, com liberdade, autonomia, consciência crítica e responsabilidade" (p.13). Sua ação enquanto docente, "com autonomia, responsabilidade, flexibilidade, resiliência", deve permitir e incentivar "a abertura a diferentes opiniões e concepções pedagógicas" baseando suas decisões "em princípios éticos, democráticos, inclusivos, sustentáveis e solidários, para que o ambiente de aprendizagem possa refletir esses valores" (p.13). Assim como deve construir sua autonomia, também deve apoiar "o estudante na construção de sua autonomia como aprendente" (p.15).

Essa diretriz deseja fortemente a autonomia docente com forte apelo à responsabilização pela sua própria formação e pela produção de estudantes autônomos. Podemos relacionar essa dimensão com o que discutimos anteriormente com Gallo (2018) na utilização ainda mais contundente das técnicas do governo de si para empreender-se enquanto profissional e indivíduo, destituído de contexto social, cultural, político, econômico, para mudanças de atitudes e condutas. Ou seja, seu papel é produzir sujeitos autogovernáveis assim como ele. Para Pires e Cardoso (2020), essa diretriz curricular, com o aporte de tecnologias biopolíticas, busca intervir na ação docente para garantir a governamentalidade da população, a partir de sua conduta e se direcionando à conduta dos discentes que constituirão a classe trabalhadora e consumidora. Dessa forma, almeja a produção de sujeitos dóceis, autorresponsáveis, pragmáticos, resilientes, em nome de uma "educação de qualidade".

É nesse sentido que a diversidade é citada, enquanto dado que deve ser observado na docência. As ações docentes devem prezar pelo "compromisso com formas de conduta que 
respeitem e valorizem a diversidade" (BRASIL, 2020, p.5) e utilizá-la como "recurso enriquecedor da aprendizagem" (p.8). A diversidade, vista como dado natural, não se apresenta com dimensões indicadas ou processos de produção, mas como recurso de aprendizagem para ser criativo ou inovador. Ela também aparece enquanto característica inerente à condição humana a ser observada por futuros docentes no cuidado de si, da sua saúde física e emocional, assim como no desenvolvimento do "autoconhecimento e o autocuidado nos estudantes" (p.13) no lidar com suas emoções e com as emoções alheias. Para isso, defende que no ato da docência deve-se:

exercitar a empatia, o diálogo, a resolução de conflitos e a cooperação, fazendose respeitar e promovendo o respeito ao outro e aos direitos humanos, com acolhimento e valorização da diversidade de indivíduos e de grupos sociais, seus saberes, identidades, culturas e potencialidades, sem preconceitos de qualquer natureza, para promover ambiente colaborativo nos locais de aprendizagem (BRASIL, 2020, p.13)

Nesse sentido, a consideração da diversidade, sem revelar as relações de poder e os processos de diferenciação que produzem a diferença, vai em direção à promoção de atitudes não preconceituosas. A BNC parece advogar pelas estratégias descritas a partir de Silva (2000): a estratégia liberal e abordagem terapêutica. Cabendo ao docente desenvolver em si e em seus alunos, como responsabilidades individuais, atitudes e valores de respeito e acolhimento a indivíduos e sociedades diversas para resolver os problemas da intolerância. $\mathrm{A} \mathrm{BNC}$ corresponde às críticas feitas pelos autores que discutimos em torno do uso da diversidade em prol da tentativa de apaziguar e apagar os conflitos inerentes à produção das desigualdades e das diferenças, para permitir um ambiente harmônico, pacífico e colaborativo, sem tensões de nenhuma natureza, que mantém intactas as normas impostas e perpetua as formas de normatização no ambiente escolar, a partir da produção de sujeitos efetivos, dóceis e governáveis.

\section{Considerações Finais}

Enquanto artefato cultural de produção de sujeitos, as diretrizes curriculares para formação docente se colocam também enquanto produto das relações de poder que estiveram envolvidas no contexto de sua fabricação e revelam os desejos desse currículo nos processos de subjetivação docente. Para realizar tal propósito, essas orientações curriculares se apresentam enquanto dispositivos de governamento que subjetivam e assujeitam os indivíduos envolvidos nos processos educativos enquanto cidadãos, democráticos, trabalhadores e, também, livres, emancipados, autônomos, críticos, criativos, líderes e inovadores, para posteriormente enfatizar a necessidade de sujeitos responsáveis, autocuidadores e autogovernáveis. 
As DCN de 2015 incluíram nos currículos para a formação docente a diversidade e a diferença enquanto conhecimento e dimensão do processo formativo que impacta o currículo. Podemos refletir que, apesar de não estar restrita à tolerância, à valorização e ao respeito ainda não aponta para a centralidade da multiplicidade. Elas se articulam para adicionar identidades outras que precisam ser consideradas para além do que já existe, sem prezar pelo questionamento das relações que produziram o existente e que impuseram o diverso e o diferente como tal. A partir da diretriz e das teorias em que se embasou, a discussão poderia se complexificar para questionar as normas e desconstruí-las, proliferar a diferença e trazer para os currículos oficiais as marcas da invenção, da soma e potencializar o processo educativo. Não queremos dizer, porém, que isso não possa ser feito, ou já tem sido feito, em algum momento, espaço, instituição, em currículos oficiais específicos ou em currículos menores, principalmente.

Em um momento anterior ao atual, visto como de avanços e vitórias de grupos e indivíduos até então marginalizados nas políticas, inclusive nas educacionais, a ausência de bases que problematizassem a diferença e suas condições de produção dentro das relações de poder, não deu conta de perceber e de impedir o avanço de discursos dos que buscaram frear o processo das conquistas, ainda incipientes e ancoradas em bases não sólidas. Assim, uma outra Diretriz foi aprovada buscando efetivamente apaziguar os conflitos que produzem desigualdades e negar os processos de produção das diferenças, naturalizando e reforçando às normatizações que as invisibilizam.

Seria pertinente compreender como as instituições e cursos de formação docente negociam as determinações a que devem atender para localizar as formas de resistências ou as conformações a essas normativas e aos discursos que produziram e foram produzidos nessas diretrizes como verdades às quais se fíliam ou não. Os processos de formatação de um currículo, seus anseios, desejos de governo e de subjetivação nos auxiliam a desnaturalizar seus princípios, seus objetivos e suas normas para dar espaço à invenção de um "currículo como espaço de possibilidades e como território onde forças possam 'deformar' as formas de um currículo, instaurando o movimento que é fundamental para o aprender" (PARAÍSO, 2015, p.50), comprometendo irreversivelmente a compulsão por bases e diretrizes comuns com desejos de unificação e fixidez.

\section{Referências}

BAMPI, Lisete. Currículo como tecnologia de governo de cidadãs e cidadãos. Anais $\mathbf{2 3}^{\mathbf{a}}$ Reunião da ANPEd, GT-Currículo, 2000.

BRASIL, Conselho Nacional de Educação. Parecer CNE/CES n776, de 03 de dezembro de 1997. Orientação para as diretrizes curriculares dos cursos de graduação. Brasília, 03 de dezembro de 1997.

BRASIL, Conselho Nacional de Educação. Resolução CNE/CP no 1 de 18 de fevereiro de 2002. Institui Diretrizes Curriculares Nacionais para a Formação de Professores da Educação Básica, em nível superior, curso de licenciatura, de graduação plena. Diário Oficial da União, Seção 1, p. 31, Brasília, 9 de abril de 2002.

BRASIL, Conselho Nacional de Educação. Resolução CNE/CEP $\mathbf{N}^{\circ} \mathbf{2}$, de $\mathbf{1}^{\mathbf{0}}$ de julho de 2015. Define as 
Diretrizes Curriculares Nacionais para a formação inicial em nível superior (cursos de licenciatura, cursos de formação pedagógica para graduados e cursos de segunda licenciatura) e para a formação continuada. Diário Oficial da União, Seção 1, pp. 8-12, Brasília, 2 de julho de 2015 (a).

BRASIL, Conselho Nacional de Educação. Parecer CNE/CEP No 2, de 9 de junho de 2015. Diretrizes Curriculares Nacionais para a Formação Inicial e Continuada dos Profissionais do Magistério da Educação Básica. Diário Oficial da União, Seção 1 p. 13. Brasília, 25 de junho de 2015 (b).

BRASIL, Conselho Nacional de Educação. Parecer CNE/CEP No 22, de 7 de novembro de 2019. Diretrizes Curriculares Nacionais para a Formação Inicial de Professores para a Educação Básica e Base Nacional Comum para a Formação Inicial de Professores da Educação Básica (BNC-Formação). Diário Oficial da União, Seção 1, p. 142. Brasília, 20 de dezembro de 2019.

BRASIL, Conselho Nacional de Educação. Resolução CNE/CP Nº 2, de 20 de dezembro de 2019. Define as Diretrizes Curriculares Nacionais para a Formação Inicial de Professores para a Educação Básica e institui a Base Nacional Comum para a Formação Inicial de Professores da Educação Básica (BNC-Formação). Diário Oficial da União, Seção 1, pp. 87 -90. Brasília, 10 de fevereiro de 2020.

CARDOSO, Lívia de Rezende; GUARANY, Ann Letícia Aragão; UNGER, Lynna Gabriella Silva; PIRES, Manuella de Aragão. Gênero em políticas públicas de educação e currículo: do direito às invenções. Revista e-curriculum, v. 17, n. 4. 2019. Disponível em: https://doi.org/10.23925/1809-3876.2019v17i4p1458-1479 Acessado em: 28 de abril de 2020.

CASTRO, Rodrigo Batista de. Eficácia, Eficiência e Efetividade na Administração Pública. Anais do 30º encontro da ANPAD. Salvador, setembro de 2006.

CORAZZA, Sandra; TADEU, Tomaz, Composições. Belo Horizonte: Autêntica, 2003.

CORAZZA, Sandra Mara. Currículos alternativos/oficiais: o(s) risco(s) do hibridismo. Revista Brasileira de Educação. n.17, p.100-114, Rio de Janeiro, 2001(a). Disponível em: http://dx.doi.org/10.1590/S141324782001000200008 . Acessado em: 02 de outubro de 2018.

CORAZZA, Sandra. O que quer um currículo?. Pesquisas pós-críticas em Educação. 3ed.

Petrópolis, RJ: Vozes, 2001(b).

DOURADO, Luiz Fernandes; TUTTMAN, Malvina Tania. Apresentação do Dossiê Temático Formação do Magistério da Educação Básica nas Universidades Brasileiras: institucionalização e materialização da Resolução CNE/CP n ${ }^{\circ}$ 02/2015. Formação em Movimento. v. 1, n. 2 , p. 197-217,jul./dez. 2019

FREITAS, Fabrício Monte; SILVA, João Alberto da; LEITE, Maria Cecília Lorea. Diretrizes invisíveis e regras distributivas nas políticas curriculares da nova BNCC. Currículo sem Fronteiras, v.18, n.3, p.857-870, set/dez, 2018

FOUCAULT, Michel. No governo dos vivos: Curso no Collège de France, 1979-1980 (excertos). Nildo Avelino (Org.) - São Paulo: Centro de Cultura; Rio de Janeiro: Achiamé, 2011

GALLO, Silvio. Educação entre o Governo dos Outros e o Governo de Si. In: RESENDE, Haroldo de (Org.). Michel Foucault - A Arte Neoliberal de Governar e a Educação. São Paulo: Intermeios, 2018, p. 211-223.

GARCIA, Maria Manuela Alves. Reformas curriculares e formação inicial: saberes e profissionalização. Educação Unisinos. V19(1), p. 57-67, janeiro/abril 2015.

HENRIQUES, Ricardo; FRANCO, Cláudia Tereza Signori; TELES, Jorge Luiz (orgs.). Educação na diversidade: como indicar as diferenças? Brasília: Secretaria de Educação Continuada, Alfabetização e Diversidade, 2006. Disponível em: http://unesdoc.unesco.org/images/0015/001545/154578por.pdf. Acessado em: 10 de outubro de 2018.

MACEDO, Elizabeth; RANNIERY, Thiago. Políticas públicas de currículo: diferença e a ideia de público. Currículo Sem Fronteiras, v. 18, p. 739-759, 2018.

MILLER, Peter; ROSE, Nikolas. Governando o presente: gerenciamento da vida econômica, social e pessoal. São Paulo: Paulus, 2012. 
PARAÍSO, Marlucy Alves. Diferença no currículo. Cadernos de Pesquisa. v. 40, p. 587-604, 2010

PARAÍSO, Marlucy Alves. Um currículo entre formas e forças. Educação (PUCRS. Impresso), v. 38, p. 4958,2015

PETERS, Michael. Pós-estruturalismo e filosofia da diferença. Trad. Tomas Tadeu da Silva. Belo Horizonte: Autêntica, 2000.

PIRES, Manuella de Aragão; CARDOSO, Lívia de Rezende. BNC para formação docente: um avanço às políticas neoliberais de currículo. Série-Estudos - Periódico Do Programa De Pós-Graduação Em Educação Da UCDB. 11 set. 2020. DOI: https://doi.org/10.20435/serie-estudos.v0i0.1463.

POPKEWITZ, Thomas S. História do currículo, regulação social e poder. In: Silva, Tomaz Tadeu da. (org.). O sujeito da educação: estudos foucaultianos. Petrópolis, Rio de Janeiro: Vozes, 1994

RODRIGUES, Tatiane Cosentino; ABRAMOWICZ, Anete. O debate contemporâneo sobre a diversidade e a diferença nas políticas e pesquisas em educação. Revista Educação e Pesquisa, São Paulo, v. 39, n. 1, p. 15-30, jan./mar. 2013.

SILVA, Tomaz Tadeu da. Apresentação. In: GOODSON, Ivor. Etimologias, epistemologias e o emergir do currículo. Currículo: teoria e história. Petrópolis: Vozes, 1995, p.29-44.

SILVA, Tomaz Tadeu. A produção social da identidade e da diferença. In: SILVA, Tomaz Tadeu (org. e trad.). Identidade e diferença: a perspectiva dos estudos culturais. Petrópolis: Vozes, 2000. p. 73-102.

SILVA, Monica Ribeiro da. Currículo e competências: a reforma do Ensino Médio e as apropriações pelas escolas. Educação Unisinos, volume 14, número 1, janeiro-abril, 2010

VARELA, Julia. Categorias espaço-temporais e socialização escolar: do individualismo ao narcisismo. In: Costa, Marisa Vorraber (org.). Escola Básica na virada do século: cultura, política e educação. 2 ed. São Paulo: Cortez, 2000.

WALSH, Catherine. Interculturalidade crítica e pedagogia decolonial: in-surgir, re-existir e re-viver. In. CANDAU, Vera Maria (Org.). Educação intercultural na América Latina: entre concepções, tensões e propostas. Rio de Janeiro: 7 Letras, 2009. p. 12-43.

\section{Correspondência}

Ann Letícia Aragão Guarany: Doutoranda em Educação no Programa de Pós-Graduação em Educação da Universidade Federal de Sergipe - UFS. Mestra em Educação e Licenciada em Ciências Biológicas pela UFS. Técnica em assuntos educacionais na UFS. Pesquisa na área de formação de professores, currículo e gênero.

E-mail: annguarany@gmail.com

Lívia de Rezende Cardoso: Professora do Programa de Pós-Graduação em Educação (PPGED) e do Departamento de Biologia (DBI) da Universidade Federal de Sergipe. Doutora pelo Programa de PósGraduação em Educação, Conhecimento e Inclusão Social na Faculdade de Educação da Universidade Federal de Minas Gerais. Possui experiência na área de Educação e tem investigado gêneros, sexualidades, corpos e dispositivos em currículos.

E-mail: livinha.bio@gmail.com

Texto publicado em Currículo sem Fronteiras com autorização dos autores. 